\title{
Clinical Presentation of Hypogonadotropic Hypogonadism in 18-Year-Old Man: Case Report
}

\author{
Rosy Nur Febriani $^{1} \quad$ Tjahjo Djojo Tanojo ${ }^{2}$ \\ 1.Andrology Specialist Program, Faculty of Medicine Universitas Airlangga and Dr. Soetomo General Academic \\ Hospital, Surabaya, Indonesia \\ 2. Andrology Clinic Dr. Soetomo General Academic Hospital, Surabaya, Indonesia
}

\begin{abstract}
The absence of spontaneous pubertal development characterized idiopathic hypogonadotropic hypogonadism $(\mathrm{IHH})$ as a result of low levels of sex steroids and gonadotropins with normal pituitary function. An 18-year-old man came to the Andrology Poly of RSUD Dr Soetomo with complaints that his penis was small. After being examined, the result showed that he had pitched voice, lipomastia, penis length $4.5 \mathrm{~cm}$, penis circumference $4 \mathrm{~cm}$, and found coronal hypospadias. There was no publicity yet. The size of the right and left testes was $\pm 1 \mathrm{cc}$ with a supple consistency and was inside the scrotum. Karyotyping result was $46, \mathrm{XY}$. The result of the hormone indicated that the FSH, LH and testosterone levels were low. The results of testicular ultrasound showed that the right and left testes in the scrotum and on abdominal ultrasound had no visible picture of the uterus. The patient was diagnosed with IHH with coronal hypospadias. The patient was given counselling, information and education about the disease he suffered, a therapy plan to be given, and the need to make lifestyle modifications. This case report describes the clinical presentation of a male patient with hypogonadotropic hypogonadism.
\end{abstract}

Keywords: Idiopathic hypogonadotropic hypogonadism, mikropenis, hipospadia coronal

DOI: $10.7176 / \mathrm{JHMN} / 85-01$

Publication date: January $31^{\text {st }} 2021$

\section{Introduction}

The absence of spontaneous pubertal development characterizes idiopathic hypogonadotropic hypogonadism (IHH) as a result of low levels of sex steroids and gonadotropins with normal pituitary function. ${ }^{1}$ Idiopathic hypogonadotropic hypogonadism is divided into two categories, namely Kallmann Syndrome and normosmic $\mathrm{IHH}^{2}$ Incident varies from 1: 10,000 - 140,000 with a ration of male: female of 4: 1 with men every 1: 8000. In most patients with $\mathrm{IHH}$, the physiological response to GnRH restores normal levels of the pituitary and gonadal hormones, allowing testicular growth and spermatogenesis in men. ${ }^{1}$

Hypogonadotropic hypogonadism can cause micropenis. Hypogonadotropic hypogonadism is the most common cause of micropenis. Micropenis is a condition where the penis is in a normal shape, but its size is less than $2.5 \mathrm{SD}$, meaning below the average size for age . ${ }^{3}$

\section{Case Report}

An 18-year-old male patient came to the Andrology Clinic of Dr. Soetomo Surabaya with complaints that his penis was small. He was circumcised in the fifth grade. There were difficulties at the time of circumcision, but it was doable. The patient had had wet dreams during junior high school. He never masturbates. The patient feels attracted to women. So far, he can urinate in a standing position.

In the history of the patient's mother pregnancy, the patient was her first pregnancy. There were no health problems during pregnancy, and she has never used drugs. In the history of maternal labor, the patient was born spontaneously, gestational age 37 weeks, was born at term, birth weight 3100 grams and was born assisted by a midwife. The patient has two siblings. Family history of the same disease was denied. The patient's history of development including sensory and motor development was said to be within normal limits. Other medical history was refuted.

Physical examination showed that the patient is $175 \mathrm{~cm}$ tall and $83 \mathrm{~kg}$, had high pitched voice, had right and left lipomastia, his stomach circumference $100 \mathrm{~cm}$, his hand span $182 \mathrm{~cm}$, and his torso length $78 \mathrm{~cm}$. The external genitalia examination showed that there was coronal hypospadias, penis length was $4.5 \mathrm{~cm}$, penis circumference was $4 \mathrm{~cm}$, the urethral estuary was not at the end, the right and left scrotum was high, and there was no pubic hair. Internal genitalia examination found that the testes on both sides were inside the scrotum, the volume of the testes on both sides was $\pm 1 \mathrm{cc}$ with the consistency of the testes on both sides being rubbery. The vas deferens, funiculus spermaticus, epididymis were difficult to evaluate.

Supporting examinations were also carried out through ultrasound examination of the testes and abdomen, hormonal laboratory tests and karyotyping test. On testicular ultrasound examination, the results showed that the right testis was visible in the right scrotum with the size $+/-0.8 \times 0.5 \times 1 \mathrm{~cm}$ and the left testicle was visible in the left scrotum with the size was $+/-0.7 \times 0.5 \times 1.1 \mathrm{~cm}$. On abdominal ultrasound examination, the uterus was not seen. On hormonal laboratory examination, FSH was $0.50 \mathrm{mIU} / \mathrm{ml}$, LH $0.19 \mathrm{mIU} / \mathrm{ml}$, testosterone $24.60 \mathrm{ng} / \mathrm{dl}$ and 
estradiol $15.25 \mathrm{pg} / \mathrm{mL}$. The results of the karyotyping examination were 46, XY. HASIL PEMERIKSAAN ANALISA KROMOSOM

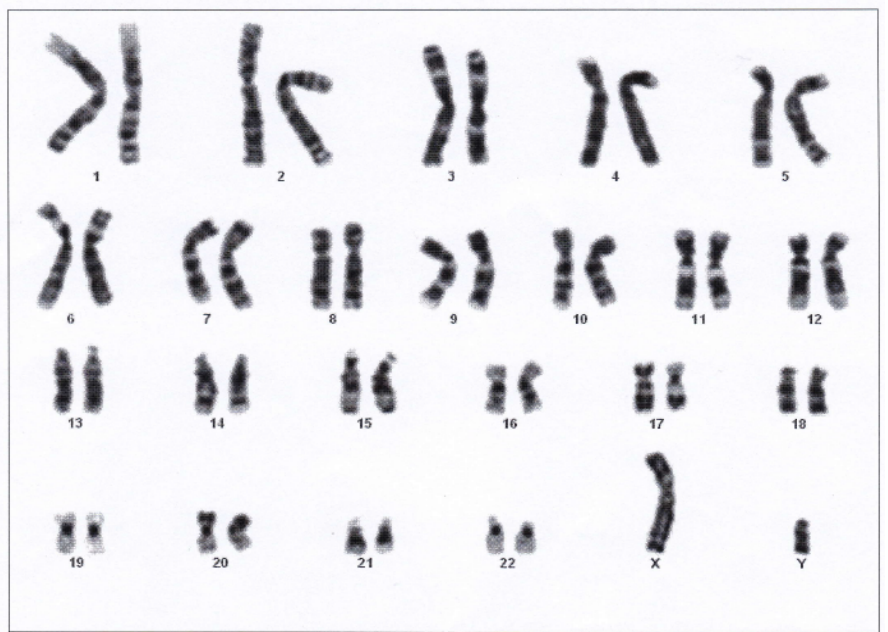

Figure 1. Karyotyping examination results

Based on the medical history, physical examination and investigations, the patient was diagnosed with idiopathic hypogonadotropic hypogonadism with coronal hypospadias. Therapy is chosen to provide counselling, information and education to patients about the patient's condition, therapy plans and the need for lifestyle modifications to improve the patient's nutritional status. The therapy given to the patient was an injection of human chorionic gonadotropin (hCG) $3000 \mathrm{IU}$ subcutan (sc) twice a week with the hCG challenge test and was referred to the Urology department for hypospadias repair.

\section{Discussion}

It is reportedly an 18-year-old man with complaints that his penis is small. On physical examination, the patient's penis length was $4.5 \mathrm{~cm}$. The penis length of the patient is less than $2.5 \mathrm{SD}$, meaning below the mean size according to age so that the patient can be said to have a micropenis. ${ }^{3,4,5}$ The causes of micropenis can be divided into three causes: hypogonadotropic hypogonadism due to pituitary / hypothalamic insufficiency, hypergonadotropic hypogonadism due to testicular insufficiency primary, and idiopathic. ${ }^{4}$

Patients with micropenis need hormonal examinations to help diagnose its cause. Laboratory tests that are needed include gonadotropin and testosterone levels. Other pituitary hormone tests can also be checked if needed. ${ }^{4}$ Hormonal examinations were conducted to the patient and showed that the FSH, LH and testosterone levels are low, while the estradiol is within normal limits so that it can be said that the patient is in a hypogonadotropic hypogonadic condition.

Hypogonadotropic hypogonadism can be congenital or acquired. Congenital hypogonadotropic hypogonadism is divided into anosmic hypogonadotropic hypogonadism (Kallmann syndrome) and congenital normosmic isolated hypogonadotropic hypogonadism (idiopathic hypogonadotropic hypogonadism). Acquired hypogonadotropic hypogonadism can be caused by drugs (sex steroids and GnRH analogues), infiltrative or infectious pituitary lesions, hyperprolactinemia, pituitary/brain radiation, excessive exercise, alcohol or drug abuse and systemic diseases (hemochromatosis, sarcoidosis, and histiocytosis X) ) ${ }^{6}$

On physical and genital examination, there is a high pitched voice, lipomastia, abdominal obesity (abdominal circumference $100 \mathrm{~cm})^{7}$, coronal hypospadias, high scrotum, supple testes with $\pm 1 \mathrm{cc}$ right and left testicular volume. The patient is examined for karyotyping (46, XY karyotyping results) and ultrasound of the testes and abdomen. Abdominal ultrasound results show no uterus, and testicular ultrasound results showed that the right testis is visible in the right scrotum with the size $+/-0.8 \times 0.5 \times 1 \mathrm{~cm}$ and the left testicle is visible in the left scrotum with the size $+/-0.7 \times 0.5 \times 1.1 \mathrm{~cm}$.

There is no anosmia/hyposmia in the patient so that the diagnosis of Kallmann Syndrome czn be ruled out. Patient denies using drugs (sex steroids and GnRH analogues), history of pituitary/brain radiation, excessive exercise, alcohol or drug abuse. The patient do not have headaches, visual field disorders, ptosis, facial pain, or diplopia (complaints that lead to pituitary tumors). ${ }^{8}$ Hypogonadotropic hypogonadism is considered idiopathic $(\mathrm{IHH})$ when there is an isolated deficiency of GnRH secretion in individuals over 18 years.

The patient has coronal hypospadias. The hypogonadotropic state of hypogonadism do not influence the incident of hypospadias. Early penile development and growth occurs between 8 and 14 weeks of pregnancy. The penis requires testosterone for normal morphogenesis and growth. The hCG hormone produced by the mother (placental) during pregnancy stimulates the testicular fetus to produce testosterone. Therefore it can be said that 
the morphogenesis of the penis is dependent on maternal hCG. ${ }^{9}$ The patient is referred to the Urology department for hypospadias repair. The goal of hypospadias repair is to achieve normal cosmetic and function. ${ }^{10}$

Hypogonadotropic therapy for hypogonadism depends on the patient's desire for future fertility. Hormone replacement with testosterone is the definitive treatment for hypogonadism. Androgen replacement is indicated for men who already have children or do not desire pregnancy, and testosterone therapy is used to reverse the symptoms and signs of hypogonadism. On the other hand, GnRH or gonadotropin therapy is the best choice for men who want to have children. ${ }^{6}$ This patient is unmarried, so the choice of therapy is hCG.

Treatment of hCG is given intramuscularly or subcutaneously. The usual dose is 1500-3000 IU given twice per week for 8-12 weeks; adjustments must be made to achieve the testosterone level within the normal range. Sometimes it may be necessary to reduce the dose of hCG due to an increase in testosterone levels or the development of gynecomastia caused by an increase in testosterone levels aromatizing to estradiol. ${ }^{11}$ In this case, the patient should provide with his condition and the treatment plan to be given.

\section{Conclusion}

This case report describes the clinical presentation of a male patient with hypogonadotropic hypogonadism. Medical history, physical examination and investigations are needed to find the cause. This patient received hCG injection therapy and is consulted to the Urology department for hypospadias repair. Periodic monitoring is required both from the history, physical examination and the results of laboratory tests.

\section{References}

1. Kulvinder, K.K., Allahbadia, G.N., Singh, M. Idiopathic Hypogonadotropic Hypogonadism- An Update on the Aetiopathogenesis, Management of IHH in Both Males and Females-An Exhaustive Review. Advances in Sexual Medicine. 2016: 6: 51. DOI: 10.4236/asm.2016.64007

2. Topaloğlu, A.K. Update on the Genetics of Idiopathic Hypogonadotropic Hypogonadism. J Clin Res Pediatr Endocrinol. 2017;9(Suppl 2):113-122. DOI: 10.4274/jcrpe.2017.S010

3. Palmer, L. S. and Palmer J. S. Management of Abnormalities of the External Genitalia in Boys. In Wern, A. J., Kavaussi, L. R., Partin, A. W., Peters, C. A. editors. Campbell-Walsh Urology. $11^{\text {th }}$ ed. Philadelpia: Elsevier; 2016; p 3376

4. Hatipoğlu, N. and Kurtoğlu, S. Micropenis: Etiology, Diagnosis and Treatment Approaches. J Clin Res Pediatr Endocrinol. 2013;5(4):217-223. DOI: 10.4274/Jcrpe.1135

5. Tsang, S. When Size Matters: A Clinical Review of Pathological Micropenis. National Association of Pediatric Nurse Practitioners. New York: Elsevier; 2010;p 233.

6. Fraietta, R., Zylberstejn D.S., Esteves, S.C. Hypogonadotropic Hypogonadism Revisited. Clinics. 2013;68(S1):81-88.

7. WHO. Waist Circumference and Waist-Hip Ratio: Report of a WHO Expert Consultation. Geneva, World Health Organization (WHO), 2008. P 28

8. Japardi, I. Tumor Hipofisis. Fakultas Kedokteran Bagian Bedah Universitas Sumatera Utara. 2002. USU digital library. p2

9. Kurzrock, E.A. and DeLair, S. Hypospadias and Kallmann's syndrome: Distinction between morphogenesis and growth of the male phallus. Journal of Pediatric Urology. 2006;2, 516. doi:10.1016/j.jpurol. 2005.11.002

10. van der Horst, H.J.R. and de Wall, L.L. Hypospadias, all there is to know. Eur J Pediatr. 2017;176:435-441. DOI 10.1007/s00431-017-2864-5

11. Zitzmann M., Behre H.M., Kliesch, S. Gonadotropin Treatment in Male Infertility. J Journal of Reproductive Medicine and Endocrinology. 2013; 10 (Special Issue 1). p25 